\title{
Investigación \\ El patrimonio inmaterial de los poblados de colonización: memoria colectiva y culturas del trabajo
}

Pablo Palenzuela Chamorro

Departamento de Antropologia Social. Universidad de Sevilla

\section{Resumen}

Los poblados de la colonización agraria en Andalucia son parte del patrimonio etnológico andaluz. El proceso mediante el cual se construye su identificación local tiene como uno de sus referentes al patrimonio inmaterial, junto al territorio y a los contenidos del patrimonio material. La memoria colectiva y las culturas del trabajo, como parte de ese patrimonio intangible, actúan como catalizadores del proceso de emergencia de una nueva entidad local en un espacio social creado con fines económicos y sociales, urbanisticamente ordenado y tutelado. El poblado de colonización responde a las caracteristicas de los paisajes culturales al ser un espacio culturalmente transformado a partir de una estrategia de colonización agraria y su puesta en valor; mediante iniciativas públicas que promuevan la investigación y la participación de la población, puede contribuir al reforzamiento de su cohesión social y al descubrimiento de sus posibilidades como Itinerario Cultural de Andalucia.

\section{Palabras clave}

Pueblos de Colonización

Patrimonio inmaterial

Patrimonio Etnológico

Identidad cultural

Memoria colectiva

Cultura del Trabajo

Paisaje Cultural

Itinerario Cultural
"Los hombres no se limitan a vivir en sociedad, sino que producen la sociedad para vivir; en el curso de su existencia inventan nuevas maneras de pensar y de actuar sobre ellos mismos así como sobre la naturaleza que les rodea" (Maurice Godelier. Lo material y lo ideal, 1990, p. 17)

\section{Introducción}

Una interpretación reduccionista del patrimonio, que lo entendiera como el conjunto de bienes materiales de naturaleza singular (artística, monumental, auténtica, etc.) que acumulan una suficiente profundidad temporal (histórico, tradicional), podría deducir que establecer en Andalucía una relación entre Poblados de Colonización y Patrimonio es, en cierta manera, un contrasentido, debido a que dichas formas de asentamiento poblacional, surgidas en la segunda mitad del siglo XX como resultantes de una política de modernización de las estructuras agrarias y de consolidación de los latifundios, no cubren, ni en su morfología ni en su temporalidad, los requisitos exigidos para su catalogación como bienes de interés patrimonial.

Si, además, esa percepción cosificada y tradicional del patrimonio se complementa con la intencionalidad utilitaria que en muchos casos preside su "puesta en valor", buscando la rentabilidad del llamado "patrimonio de consumo", el interés patrimonial de los poblados de colonización descendería hasta el nivel suficiente como para explicar, que no justificar, las escasas iniciativas administrativas y académicas para su estudio, catalogación y protección ${ }^{2}$.

Afortunadamente, esa priorización del patrimonio material, histórico/artístico y tradicional, que ha venido orientando una parte importante de las iniciativas de catalogación y valorización, se ha visto compensada, en las últimas décadas, por el creciente interés volcado hacia el patrimonio inmaterial o intangible ${ }^{3}$. Esta reciente concepción integral del patrimonio responde adecuadamente a su doble naturaleza ideacional y material y permite abordar holísticamente su funcionalidad múltiple como factor de identidad e identificación y como recurso dentro de estrategias de desarrollo sostenible.

Por parte de las instancias políticas y de las instituciones públicas de cualquier nivel, la mayor valorización de este patrimonio inmaterial se ha plasmado tanto en iniciativas legislativas y declaraciones como en actuaciones de rescate, protección y puesta en valor, no exclusivamente rentabilista, de esos bienes intangibles que conforman, junto a los de naturaleza objetivable, el patrimonio cultural o etnológico de la humanidad ${ }^{4}$.

En el marco socio-político en el que se ubican nuestros referentes empíricos (los poblados de la colonización agraria), la Comunidad Autónoma Andaluza adoptó, como norma reguladora de su politi- 
ca sobre el patrimonio cultural, la Ley $1 / 91$ de 3 de julio, de Patrimonio Histórico de Andalucía que en su artículo 61 define el Patrimonio Etnológico como "los lugares, bienes y actividades que alberguen o constituyan formas relevantes de expresión de la cultura y modos de vida del pueblo andaluz". Esta sucinta definición es, no obstante, integradora ya que contiene tanto las manifestaciones de naturaleza inmaterial (actividades, usos, costumbres, creencias, etc.) como aquellas otras de naturaleza material (lugares, bienes, etc.) que son expresión objetivada de las anteriores. Pero, como ya avanzamos en la Guía para la Puesta en Valor del Patrimonio del Medio Rural Andaluz (Palenzuela, 2000:7), la función más importante del Patrimonio Etnológico es su carácter identificador: "Es decir, las prácticas y actividades no encierran un valor por sí mismas como manifestaciones más o menos pintorescas, sino que son relevantes por el significado que poseen para la población que participa y se ve representada e identificada en ellas".

Nuestras reflexiones sobre la valoración patrimonial de los poblados de colonización andaluces se apoyan también en las siguientes conclusiones de la Declaración de Estambul sobre Patrimonio Inmaterial adoptada en septiembre de 2002 por la III Mesa Redonda de Ministros de Cultura convocada por la UNESCO:

1. Las expresiones múltiples del patrimonio inmaterial están en los fundamentos de la identidad cultural de los pueblos y las comunidades.

2. El patrimonio cultural inmaterial crea en las comunidades un sentido de pertenencia y continuidad y es considerado como una de las fuentes principales de la creatividad y de la creación cultural.

3. La salvaguardia y la transmisión de este patrimonio inmaterial reposa esencialmente en la voluntad y en la intervención efectiva de los actores de este patrimonio.

Este último apartado de la Declaración introduce la importante cuestión de la legitimación sobre los procesos de apropiación, uso e intervención respecto a los bienes constitutivos del patrimonio inmaterial y adopta una posición claramente favorable a los agentes de ese patrimonio. Es decir, una priorización, que compartimos plenamente, del "patrimonio de uso" respecto al "patrimonio de consumo". Desde esa premisa, toda actuación para la "puesta en valor" del patrimonio debe plantearse desde los derechos de apropiación de aquéllos que construyen, conservan, transforman y trasmiten el patrimonio ${ }^{5}$.

Dentro de las múltiples expresiones del patrimonio inmaterial, a las que hace referencia el apartado $1^{\circ}$ de la Declaración de Estambul, hemos optado, teniendo en cuenta la especificidad del marco espacial y sociocultural de nuestros poblados de colonización, por centrar nuestro análisis en las siguientes expresiones:
a) La memoria colectiva
b) Las culturas del trabajo

Entendemos que dicha selección está plenamente justificada, tanto por la naturaleza claramente inmaterial de ambas categorias, lo que las integra en el campo del patrimonio intangible, como, sobre todo, por el hecho de que nuestros referentes empíricos sean núcleos poblacionales de reciente constitución, en proceso de conformación de su identificación local y con una dependencia económico-administrativa particular y por la circunstancia, nada aleatoria por cierto, de que la práctica totalidad de sus habitantes respondan al mismo perfil socio-profesional y compartan unas semejantes culturas del trabajo.

Cada una de esas expresiones del patrimonio inmaterial nos plantea un doble desafío. En primer lugar, un reto analítico y metodológico, ya que hemos seleccionado como objeto de estudio una parte de la realidad social que nos obliga a trascender el análisis formal, empirico y descriptivo para incursionar en el campo de las ideas y de las representaciones, de lo cognitivo y de lo simbólico. ${ }^{6}$ En segundo lugar, un desafío propositivo, porque pretendemos demostrar la funcionalidad de ambas categorías en la conformación de la identificación local y en la definición de estrategias colectivas para la puesta en valor del patrimonio de los poblados de colonización.

\section{Identificación local y memoria colectiva}

Aunque es habitual encontrar en la literatura científica y en el léxico político la utilización indistinta de las expresiones "identidad local" o "identificación local", nosotros preferimos utilizar esta última o, mejor aún, "procesos de identificación", cuando analizamos la génesis, consolidación y transformación de los discursos y de las prácticas sociales que construyen un "nosotros", dentro de marcos sociales de ámbito local. Con ello pretendemos evitar la reificación del concepto de identidad, al que reservamos para el análisis de las identidades sociales resultantes de la imbricación de un conjunto de factores estructurantes, entre los cuales la identidad étnica, la identidad de sexo-género y la identidad socioprofesional o cultura del trabajo tienen un alto nivel de determinación, constituyendo lo que Isidoro Moreno ha definido como "matriz identitaria" (Moreno, 1991:604). No obstante, esta diferenciación conceptual no conlleva una oposición entre ambos términos ya que, en la construcción de esos discursos que proponen un marco de adscripción local se incorporan, con mayor o menor nivel de causalidad, algunos de los tres factores estructurantes de las identidades sociales. Por ejemplo, visiones androcénticas de la historia local silenciando el papel de las mujeres en los pobla- 


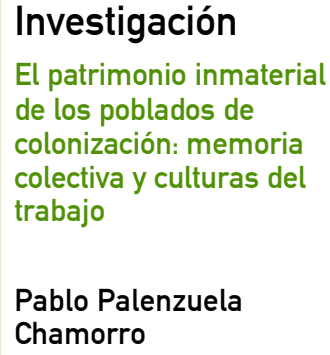

dos de colonización, construcciones etnocéntricas del "nosotros" que velan la naturaleza multiétnica del grupo o la traslación al conjunto de la población de los marcadores que definen unas determinadas culturas del trabajo.

En consecuencia, definimos la identificación local como "el conjunto de construcciones ideáticas que sobre una realidad social concreta elaboran determinados sectores sociales que, apoyándose en hechos reales o mixtificados, pretenden velar o, en su caso, enfatizar la estructura social jerarquizada y, a partir de ello, ofrecer unos referentes de identificación al conjunto de individuos que ocupan un territorio determinado" (Palenzuela y Hernández, 1995:18). Nos interesa subrayar aquí que el proceso de conformación de una determinada identificación local está articulado estrechamente con las estructuras de poder que, en las sociedades jerarquizadas, controlan los mecanismos de la producción ideológica y consiguen, en un alto grado de eficacia, que su propuesta del "nosotros" sea colectivamente aceptada?.

La memoria colectiva, y los marcos sociales que la conforman y le otorgan un sentido especifico, constituyen la urdimbre sobre la cual se tejen los procesos de identificación y los discursos que pretenden legitimar su aceptación.

La memoria colectiva, según Maurice Halbwachs, "es el proceso social de reconstrucción del pasado vivido y experimentado por un determinado grupo, comunidad o sociedad" (Halbwachs, 1950:174). Esta sucinta definición permite, no obstante, al sociólogo francés desarrollar en su clásica obra La memoire collective, publicada póstumamente en $1950^{\circ}$, toda una sociología de la memoria y de los marcos sociales que la encuadran y le dan sentido.

Para los objetivos de este trabajo, nos interesa rescatar de sus aportaciones, en primer lugar, el carácter social, es decir colectivo, del proceso que dota de un sentido compartido a los hechos sociales vividos y recordados y constituye al grupo como entidad. En segundo lugar, la constatación de que la memoria colectiva es múltiple y se transforma a medida que es actualizada por los grupos que participan en ella. En tercer lugar, la relación entre memoria colectiva e identidad que se manifiesta cuando la búsqueda de la memoria colectiva deviene en el fondo la búsqueda de unas estrategias que permiten a una sociedad o a un grupo tener conocimiento de sí mismo. Es más, para nuestro autor, la memoria es la única garantía de que el grupo sigue siendo el mismo.

Sin embargo, su aportación teórica de mayor dimensión socio-antropológica, desprendida de las connotaciones psicologistas presentes en algunos capítulos del libro, es la definición de los marcos sociales de la memoria. De entre ellos descartamos, por su
1. Plaza de la Iglesia. Adriano

2. Depósito de agua y tractor. Adriano

3. Viviendas y calle peatonal. Chapatales

4. Calle Larga y plaza. Chapatales escasa pertinencia a nuestro objetivo, los marcos familiares y religiosos y nos centraremos en los espaciales, temporales y los de clase social.

El marco espacial, que nosotros preferimos renombrar como "marco territorial" ya que el territorio es espacio socializado, son los lugares, las construcciones, los paisajes, los objetos, etc. en los que se ha ido depositando la memoria colectiva a través del proceso temporal que ha incorporado al espacio las actividades antrópicas que le dan una específica significación material y simbólica?.

Sin negar el peso específico que tiene el territorio como marco espacial de la memoria colectiva, y por consiguiente en la construcción de las identificaciones locales ${ }^{10}$, no debemos por ello caer en el determinismo ambiental que postularía al territorio, bien como factor de causalidad determinante en dichos procesos o, en otro sentido, como mero contenedor de los hechos sociales. Muy al contrario, la producción social del espacio está intimamente incardinada en las estructuras de poder que generan, por ejemplo, modelos de apropiación del territorio excluyentes, accesos diferenciados a su usufructo y orientaciones cognitivas contrastivas respecto a su percepción como referente de identificación. Por lo tanto, el territorio tiene una significación ambivalente para la identificación social, ya que funciona simultáneamente como factor de cohesión, cuando se enfatiza en los discursos el derecho de apropiación colectiva (más simbólica que jurídica), y como elemento de ruptura y diferenciación interna, cuando se fragmenta sobre la base de modelos de apropiación excluyentes.

Volviendo a los postulados de Halbwachs, en este punto nos interesa rescatar, por lo que tiene de conexión directa con el modelo de asentamiento seguido en los poblados de colonización, la estrecha relación que el citado autor establece entre los marcos espaciales y temporales y la construcción de la memoria colectiva. Por ejemplo, afirma: "Cuando el grupo social ocupa durante un largo proceso temporal un emplazamiento adaptado a sus costumbres y necesidades no sólo sus movimientos, sino sus pensamientos son regidos por la sucesión de imágenes materiales que representan los objetos exteriores" (Halbwachs, 1950:137), pero, muy al contrario, "cuando cualquier suceso nos obliga a transportarnos a un nuevo medio material, antes de adaptarnos, atravesamos por un periodo de incertidumbre" (ib.:130), en estos casos, sigue el autor, "las costumbres locales resisten a las fuerzas que tienden a transformarlas y esta resistencia permite ver mejor hasta qué punto en dichos grupos la memoria colectiva se apoya sobre imágenes espaciales" (ib.:136). En estas situaciones de desterritorialización, "el grupo no se contenta con manifestar su sufrimiento. Resiste con toda la fuerza de sus tradiciones y esta resistencia genera equilibrio en las nuevas condiciones" (ib.:139). ${ }^{11}$ 

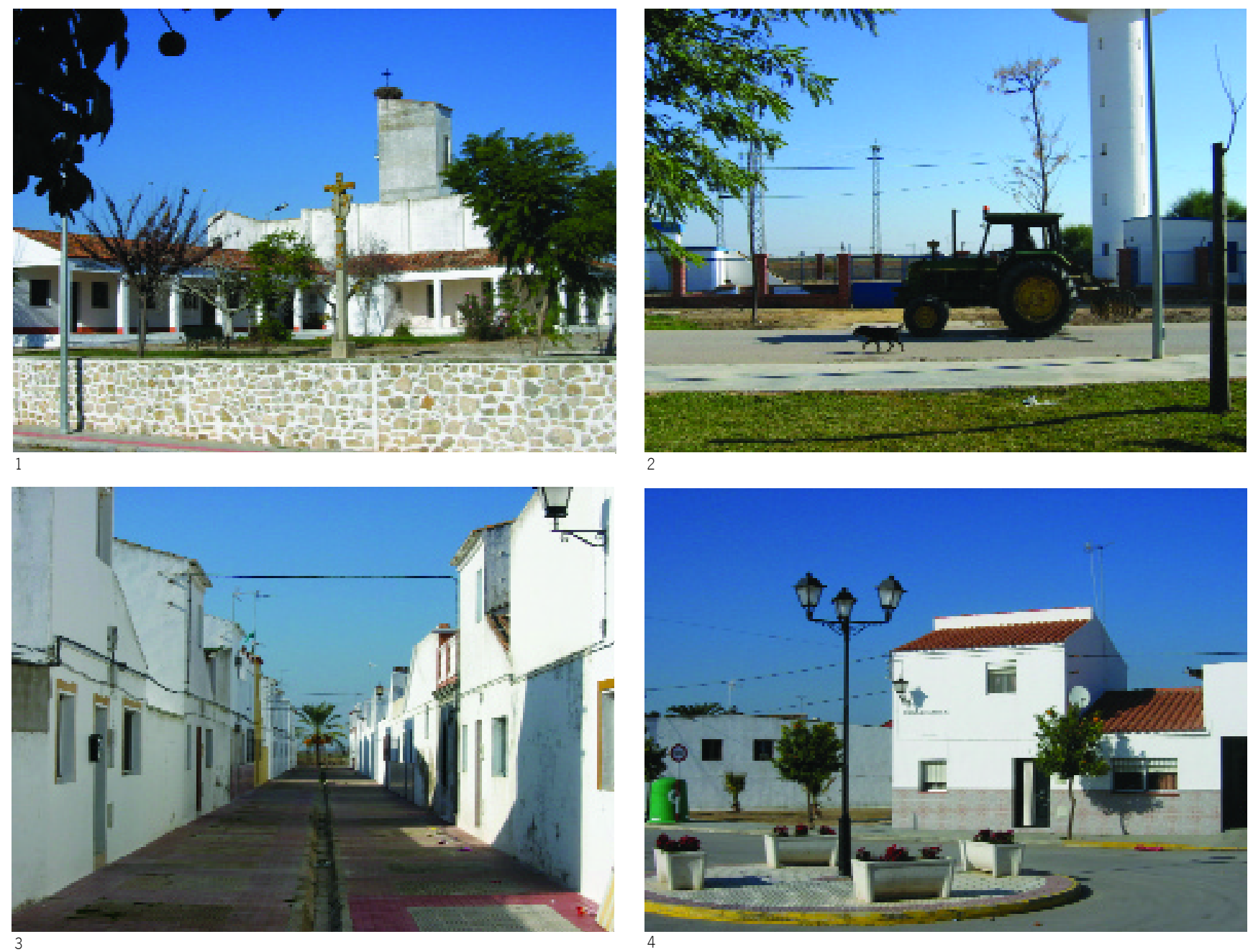

El carácter procesual y polisémico de las identificaciones locales se manifiesta en todo tiempo y lugar, pero alcanza cotas de especial significado en las circunstancias en las que el grupo se desplaza y debe adaptarse a unos marcos socioculturales nuevos y, más aún, cuando, como en el caso de las sociedades locales formadas en los poblados de colonización, no sólo el marco espacial es nuevo para muchos de sus pobladores, sino que el propio grupo debe constituirse como entidad diferenciada. En este último escenario, que es precisamente el que aqui nos interesa, la reconstrucción de la memoria colectiva, seleccionado, socializando o ritualizando los acontecimientos del pasado, diseña ese "mural de semejanzas" (Halbwachs, 1950:77) que puede funcionar como catalizador del proceso de definición de un nuevo "nosotros".

\section{Culturas del trabajo y territorio}

La centralidad del trabajo en la vida social no se expresa únicamente en los términos objetivables que constatan su funcionalidad para subvenir a las necesidades social e históricamente definidas, ni tampoco en la ponderación del tiempo social entre trabajo y no trabajo, sino que dicha centralidad alcanza su verdadera significación cuando todo lo anterior se articula con la producción de valores, significaciones y percepciones que tienen al trabajo como argumento central. Esa ideología sobre el trabajo se sustenta, y a la vez retroalimenta, la división social del trabajo, las relaciones sociales de producción y los modelos de organización técnica de los procesos de trabajo.

Esa doble centralidad material e ideacional del trabajo hace de él un factor generador de cultura. Una cultura del trabajo dialécticamente construida desde su base material (cultura técnica o "saber hacer") y su componente ideacional (identidad socio-profesional). Las culturas del trabajo (en plural, ya que no hay valores de significación universal del trabajo, aunque la ideología hegemónica pretenda homogeneizar los asignados al trabajo capitalista) se imbrican, como ya adelantamos, en la estructuración de las identidades colectivas y dotan de sentido a las prácticas sociales (tanto dentro como fuera de los tiempos y lugares del trabajo) que realizan los colectivos que comparten unas específicas culturas del trabajo ${ }^{12}$.

El marco espacial de las culturas del trabajo así entendidas no se circunscribe a los lugares de trabajo, sino que los desborda para impregnar el conjunto de relaciones sociales (laborales y extra-laborales) del individuo. El propio Halbwachs, sin llegar a adjudicar a las culturas del trabajo el nexo de relación entre los distintos espacios sociales, afirmaba: "Distinguimos en la sociedad dos zonas o ámbitos, una que llamaremos zona de la actividad técnica y otra, zona de relaciones personales (en la familia, en el mundo, etc.). Admitiremos por lo demás que esas zonas, que se podría creer tan nítidamente separadas como los periodos y lugares en donde se ejerce la profesión y aquéllos en los que ésta ya no se ejerce más, están comprometidas una con otra" (Halbwachs, 2004:309).

Por otra parte, cuando unas determinadas culturas del trabajo alcanzan, en un ámbito territorial concreto, una considerable exten- 


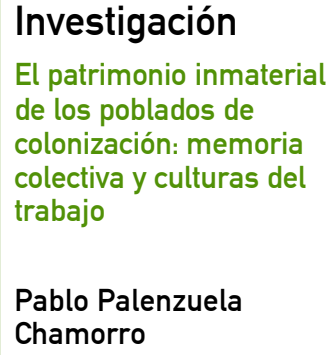

sión entre la población y/o una gran profundidad temporal, se verifica su funcionalidad como marcador de la identificación local. En estos casos, la identidad socio-profesional que comparte una buena parte de los individuos se extiende, en los discursos de identificación, al conjunto de la población, convirtiéndose de hecho en una seña de identidad de ciertas poblaciones ${ }^{13}$.

Parece evidente que los poblados de colonización, como formas de asentamiento poblacional surgidas de una política de colonización agraria ${ }^{14}$, concentraron en espacios estratégicamente localizados tanto las actividades productivas relacionadas con el trabajo en la tierra, como unas poblaciones, cuidadosamente seleccionadas que, a pesar de sus diferentes lugares de origen, compartían la identidad socio-profesional o la cultura del trabajo agricola, aunque segmentada ésta por la posición estructural diferente de colonos y obreros agrícolas respecto a la propiedad de la tierra. Por ello, podemos suponer que en esos poblados, aunque no sea excesiva su profundidad temporal, las culturas del trabajo campesinas y jornaleras y sus transformaciones, desde la creación de los poblados hasta la actualidad, forman parte del patrimonio inmaterial de esos lugares y funcionan como marcadores de identificación local.

\section{Los poblados de colonización como paisaje cultural}

La política de colonización agraria, en general, y los poblados de colonización, en particular, han suscitado, desde su origen hasta hoy, el interés analítico de especialistas en historia agraria, en sociología rural, en geografía humana, en antropología social, en ordenación del territorio y en arquitectura, principalmente ${ }^{15}$.

Estas aproximaciones multidisciplinares responden, lógicamente, a la naturaleza diversa y compleja del proceso de colonización agraria, que lo convierten en un "hecho social total" con contenidos, tan dispares pero dialécticamente articulados, como los ideológicos corporativistas, los de política social asistencialista y regeneracionista, los de modernización de las estructuras agrarias, los de asentamientos poblacionales de aluvión y los de ordenación racionalista del territorio, entre otros.

Para evaluar el impacto de la colonización agraria en la formación económico-social andaluza, resulta imprescindible hacer referencia a la obra pionera ${ }^{16}$ de J.J. Romero y F. Zoido de 1977: "Colonización agraria en Andalucía", focalizada en las zonas regables de Guadalcacín (Cádiz) y Bembézar (Córdoba). Dicha obra, además de un amplio y documentado análisis geo/económico, incorpora un capitulo, de corte más sociológico, titulado ¿Qué opinan los co-
Ionos de su situación? (pp. 219-248). En este apartado, que para nosotros cobra un especial interés, los autores intentan "averiguar la actitud subjetiva de los colonos ante la realidad de los poblados de colonización y sus perspectivas de futuro" (Romero y Zoido, 1977:220), a partir de un cuestionario "breve, redactado con urgencias y sin excesivos escrúpulos metodológicos", según reconocen los propios autores (ib.:220).

Esta aproximación a la percepción subjetiva de la realidad de los poblados, con todas las limitaciones que los autores no ocultan, aporta, sin embargo, una nueva dimensión al objeto de estudio y algunas conclusiones tentativas que conectan directamente con los objetivos de nuestro artículo. Entre ellas, la percepción diferenciada de los informantes según procedan del mismo municipio o de lugares alejados: "No es igual la situación de los que por proceder de zonas muy alejadas del poblado han sufrido o están sufriendo un fuerte desarraigo" (ib.:221) ${ }^{17}$; la valoración positiva por los colonos (en este caso no opinan los obreros) de la autonomía personal y de la independencia en el trabajo. Valoración que contrasta con la abrumadora respuesta $(84 \%$ de los entrevistados) que percibe que la solución de sus problemas depende del Estado. Finalmente, se detecta en algunas de sus manifestaciones que "la unión" es percibida como una "aspiración frustrada": "No estamos preparados para agruparnos", "Hace falta más unión", "Si los pueblos fueran en forma de cooperativa, irian mucho mejor" (ib.:248).

En el capitulo final de conclusiones, encontramos esta afirmación que remite directamente a los contenidos ideacionales de las culturas del trabajo: "El acceso a la propiedad no ha desclasado a los colonos que siguen perteneciendo en sus manifestaciones al proletariado campesino" (ib.:250).

Desde la constatación de las limitadas aportaciones para el análisis socio-cultural ${ }^{18}$ y patrimonial de los poblados de colonización andaluces y con la perspectiva temporal de varias décadas de existencia, nos atrevemos a proponer una línea de estudio e intervención que construya a los poblados de colonización como "Paisaje cultural" de Andalucía, identificando y poniendo en valor su patrimonio etnológico, con énfasis especial en dos elementos de su patrimonio inmaterial: la memoria colectiva y las culturas del trabajo.

El "paisaje cultural" es una categoría patrimonial adoptada en 1992 por el Comité del Patrimonio Mundial de la UNESCO para "enfatizar los vínculos e interacciones que se han dado entre el hombre y su entorno". El maestro de geógrafos Carl Sauer lo define asi: "El paisaje cultural es modelado desde un paisaje natural. La cultura es el agente, el área natural el medio y el paisaje cultural el resultado". En nuestra opinión, esta propuesta encierra y 
5. Equipamientos sociales. Chapatales.

6. Viiviendas reformadas. Pinzón.

sintetiza la permanente relación entre territorio y cultura, pero, como todo territorio es "espacio socializado", es decir, producto de la cultura, se hace preciso delimitar el campo semántico del paisaje cultural para no caer en el silogismo nihilista de que "si todo es paisaje cultural, paisaje cultural es nada". En consecuencia, sólo estaría justificado el empleo de esta categoría a aquellas porciones del territorio que, tanto por su morfología como por las prácticas culturales que han incidido en su transformación, funcionan como referentes materiales y simbólicos con significación particular. Por lo tanto, estamos aludiendo a aquellos espacios, objetos o conocimientos sobre los que se concentra la percepción de apropiación y de singularidad y en los que se verifica con nitidez la intervención antrópica, es decir, cultural.

Si bien es cierto que el paisaje cultural es un constructo social y procesual, no tiene por qué estar necesariamente encadenado a la tradición ni a un tipo de entorno determinado. La UNESCO clasifica los paisajes culturales en: urbanos, rurales, arqueológicos e industriales. Por ello, están en la Lista del Patrimonio de la Humanidad, por ejemplo, el paisaje cultural de la región viticola del Alto Duero en Portugal desde 2001 o la ciudad de Brasilia desde 1987 y el paisaje cultural de Aranjuez desde $2001^{19}$.

Si tomamos como referencia la definición y los componentes del paisaje cultural que adopta el Instituto del Patrimonio Histórico Español podemos fácilmente deducir que los poblados de colonización cumplen sobradamente esos requisitos:

"Paisaje cultural es el resultado de la acción del desarrollo de actividades humanas en un territorio concreto, cuyos componentes indicativos son:

1. El sustrato natural (orografía, suelo, vegetación, agua)

2. Acción humana: modificación y/o alteración de los elementos naturales y construcciones para una finalidad concreta

3. Actividad desarrollada (componente funcional en relación con la economía, formas de vida, creencias, cultura, etc.)"

Pero esta correlación objetiva entre poblados de colonización y paisaje cultural, siendo condición sine qua non, no es suficiente. Queda pendiente todo el proceso de su puesta en valor a partir de iniciativas de politica patrimonial que, partiendo de investigaciones científicas y contando con la participación de los agentes de ese paisaje cultural, reconozcan y difundan la importancia etnológica que tienen esos núcleos de población articulados a la red de agrociudades de la Baja Andalucía.

Como ya adelantamos al principio de este texto, los dos elementos de esa valorización que, por su naturaleza ideacional, deberían ser objeto de especial interés por parte de la antropología, son la re-

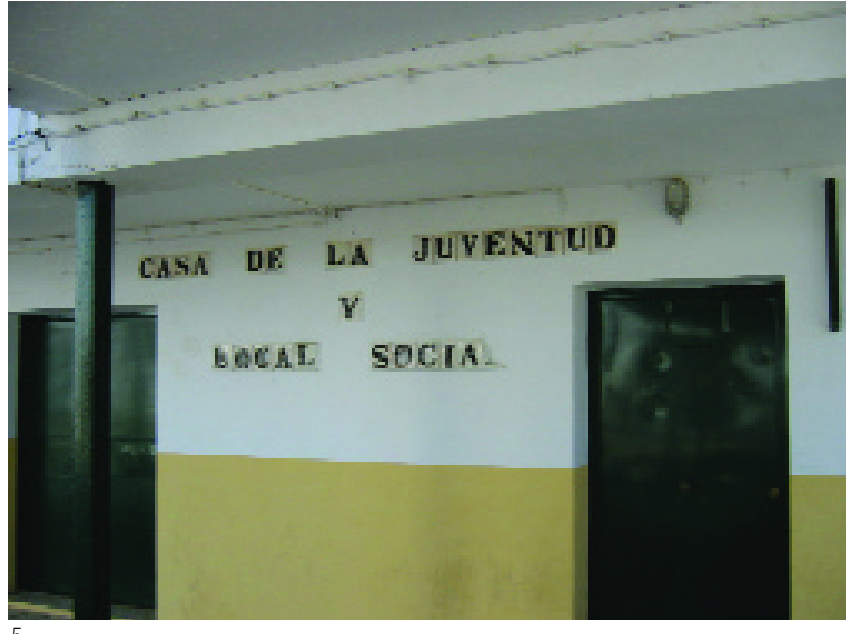

5

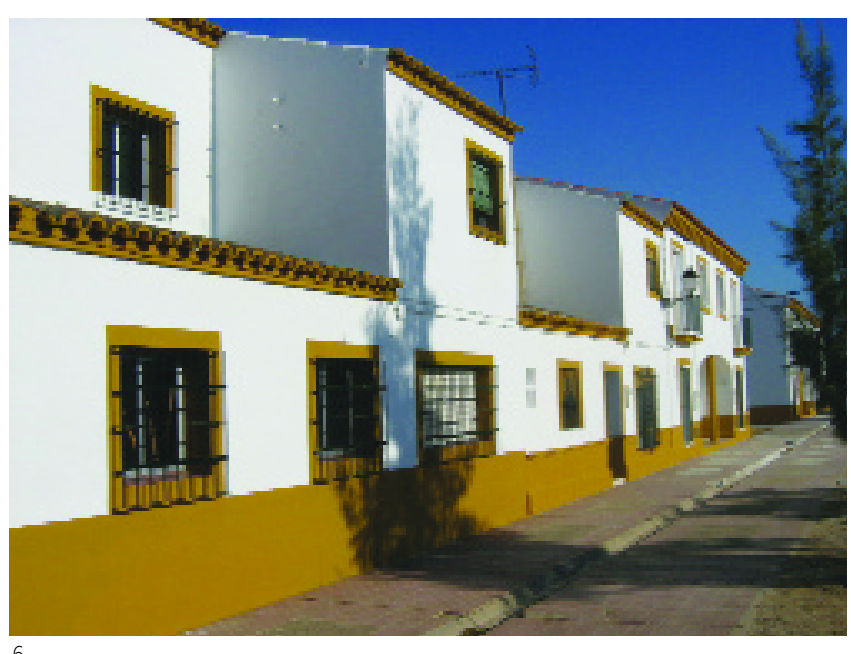

construcción de la memoria colectiva ${ }^{20}$ y su incidencia en la dirección que han adoptado los procesos de identificación local y el análisis de las culturas del trabajo (campesinas y jornaleras) y su plasmación en la transformación del territorio y en la modificación de sus aprovechamientos. Sólo a título indicativo, estas dos categorías de análisis deberían dedicar especial atención, para la recuperación de la memoria colectiva, en el proceso de instalación de los colonos, a las primeras épocas de tutela y dependencia del organismo regulador (INC o IRYDA) y de sus funcionarios, a la reproducción de tradiciones y rituales de sus lugares de origen, al impacto de calamidades (sequías, incendios, etc.), a la modificación de estrategias domésticas para incorporarse a la modernización agraria, a las primeras formas de asociacionismo cultural, recreativo, cooperativo e incluso político, a los procesos de reivindicación frente a la cabecera municipal y la consolidación, en su caso, de plataformas segregacionistas, etc. 


\section{Investigación}

El patrimonio inmaterial de los poblados de colonización: memoria colectiva y culturas del trabajo

\section{Pablo Palenzuela}

Chamorro

En lo que respecta a las culturas del trabajo y su transformación, se nos presentan como elementos de interés, entre otros, la adaptación de los jornaleros a los nuevos esquemas jerárquicos y disciplinares de la organización del trabajo en los poblados, la inserción del colono en un marco de ejercicio de su actividad totalmente controlado y tutelado por la Administración, la incorporación a la mecanización agraria y a las nuevas técnicas de cultivo, el papel de la mujer y de las ayudas familiares en la consolidación de la parcela, las formas de asociacionismo laboral y extra-laboral, los modelos de transmisión patrimonial adoptados y las formas de aprendizaje y adquisición del saber-hacer.

Si aceptamos la premisa de que los poblados de la colonización son paisajes culturales de facto, nos vemos tentados a recuperar aquí, de forma sintética, las premisas metodológicas con las que concluiamos nuestro artículo "El paisaje como patrimonio etnológico: aportaciones a su análisis desde la antropología" (Palenzuela, 2000):

a) Abordar dialécticamente lo material y lo ideacional

b) Priorizar la visión desde dentro frente a la percepción externa

c) Reconstruir el modelo etnográfico de prácticas y saberes

d) Analizar y deconstruir los discursos legitimadores de la apropiación del paisaje

e) Establecer la relación entre paisaje cultural y estructura social f) Rechazar la aprioristica superioridad de determinadas configuraciones estéticas

g) Aceptar que los resultados de la investigación tengan, para los agentes sociales, una función social de identificación y no sólo rentabilista

Finalmente, teniendo en cuenta la unidad en la diversidad del modelo de colonización agraria en Andalucía y su dispersión en un ecosistema homogéneo como la Vega del Guadalquivir, ¿qué nos impide imaginar que, al final del proceso de su puesta en valor, la red de poblados de la colonización agraria se convirtiera en uno más de los Itinerarios Culturales ${ }^{21}$ de Andalucía?

Fotos: David Palenzuela Levesque

\section{Notas}

${ }^{1}$ La profundidad temporal jugaría a favor de la consideración patrimonial de poblaciones como La Carolina, La Luisiana, Fuente Palmera, La Carlota, Prado del Rey, etc. surgidas de la política ilustrada de colonización llevada a cabo en Andalucia por el intendente Pablo de Olavide en el siglo XVIII.

${ }^{2}$ La publicación de este número monográfico de $\mathrm{PH}$ Boletín del Instituto Andaluz del Patrimonio Histórico puede representar, felizmente, un punto de inflexión en esa línea de escaso interés.

${ }^{3}$ Entre esta doble posibilidad terminológica "inmaterial o intangible", parece consolidarse la primera de ellas, al entender que el adjetivo "intangible" podría asimilarse a "inviolable", "sagrado", etc. En esta definición adoptada en 2003 por la UNESCO: "Se entiende por pa- trimonio cultural inmaterial, las prácticas, representaciones, expresiones, conocimientos y saber hacer - así como los instrumentos, objetos, artefactos y espacios culturales a ellos asociados - que las comunidades, los grupos y, en su caso, los individuos reconocen como parte de su patrimonio cultural. Este patrimonio cultural inmaterial, transmitido de generación en generación, es recreado permanentemente por las comunidades y grupos en función de su medio ambiente, de su interacción con la naturaleza y de su historia y les procura un sentimiento de identidad y de continuidad", hemos subrayado con toda intención los dos componentes sobre los que apoyaremos la identificación del patrimonio inmaterial de los poblados de colonización.

${ }^{4}$ En el cuaderno "Patrimonio Etnológico", de la Guía para la Puesta en Valor del Patrimonio del Medio Rural Andaluz, cuya edición coordinamos por encargo de la Consejería de Agricultura y Pesca (2000), se recoge una selección significativa de la normativa de protección del Patrimonio Etnológico en los ámbitos internacional, europeo, nacional y autonómico andaluz.

${ }^{5}$ En nuestro artículo publicado en el volumen 32 de esta misma revista, proponíamos como premisa metodológica para el análisis del paisaje cultural lo siguiente: "Priorización de la visión desde dentro respecto a la percepción externa. Es decir, acordar una atención especial al paisaje de uso sobre el paisaje de consumo, reconociendo la legitimidad de la intervención a aqueIlos que manejan con responsabilidad y perciben el paisaje como legado común" (Palenzuela, 2000:91)

${ }^{6}$ Es decir, "penetrar por medio de la imaginación teórica en la caja negra de los mecanismos gracias a los cuales grupos sociales con intereses parcial o profundamente contrapuestos comparten las mismas representaciones" (Godelier, 1990:32)

${ }^{7}$ Esta diferenciación conceptual entre identidad e identificación es compartida por nuestra compañera Assumpta Sabuco en su tesis doctoral, realizada en la Isla Mayor del Guadalquivir. En ella, la autora establece una distinción entre ambos conceptos sobre la base de que "si las identidades son procesuales y dinámicas, la conjunción de estas variables estructurantes (la etnicidad, el género y las culturas del trabajo) en los grupos sociales implica, fundamentalmente, una forma concreta de organizar las diferencias. Y superando las dicotomías al uso, las identificaciones son resultado de los procesos sin que ello implique que no sean a su vez objeto de modificaciones importantes" (Sabuco, 2002:32)

${ }^{8}$ Esta obra, que aparece cinco años después de la desaparición del autor en un campo de extermino nazi, retoma y desarrolla los postulados enunciados en su libro de 1925 Les cadres sociaux de la memoire, cuya traducción al castellano acaba de publicar Anthropos, 2004.

9 "La intima relación que a lo largo de un proceso histórico desarrollan las sociedades locales con el espacio que ocupan, las formas de adaptación al medio físico, los diversos tipos de apropiación, etc. generan, además de una determinada configuración espacial, unas especificas valoraciones, percepciones y representaciones colectivas de la territorialidad" (Palenzuela y Hernández, 1995:122).

10 "El territorio, por tanto, en sus aspectos más físicos o en su ordenación socio-política, no genera identidad, sino que constituye uno más de los elementos posibles sobre los que se construyen las identificaciones colectivas" (Sabuco, 2002:39)

${ }^{11}$ La Antropología Social ha generado una extensa bibliografía en el estudio de los procesos de resignificación y de hibridación de identidades sociales en contextos de desterritorialización. Los flujos migratorios y el desplazamiento forzado de poblaciones (éxodos, exilios, destierros, etc.) siguen ofreciendo a los antropólogos un atractivo laboratorio para el estudio de fenómenos de reproducción de identidades fuera de los marcos territoriales en los que se generaron. Sólo a título de ejemplo, podríamos citar los trabajos de Emma Martín sobre los andaluces emigrados a Cataluña o los de Teófilo Altamirano sobre la reproducción de la identidad andina entre los quechuas emigrados a Lima.

${ }^{12}$ Estas consideraciones sobre la potencialidad epistemológica del concepto "culturas del trabajo" se encuentran mucho más elaboradas en nuestro artículo: "Las culturas del trabajo: una aproximación antropológica", en Sociología del Trabajo, vol. 24, 1995, pp. 3-28.

${ }^{13}$ En Andalucía, este proceso de territorialización de culturas del trabajo, se constata en casos como Macael y el mármol, Ubrique y la marroquinería, Jérez y la viticultura, Linares y la automoción, Jabugo y el jamón, etc. Precisamente a partir de esta relación entre culturas del trabajo y espacio social se realizó, bajo nuestra dirección, la tesis doctoral de Javier Hernández 
sobre las culturas del trabajo de HYTASA y el barrio sevillano del Cerro del Águila. Cf. J. Hernández Ramirez, 1999.

${ }^{14}$ Algún estudioso de los poblados de colonización ha encontrado un paralelismo entre la ordenación del territorio surgida de la colonización agraria y las "colonias industriales" (la fábrica y su barrio) creadas durante la revolución industrial de finales del XIX.

${ }^{15}$ La magna obra editorial en cuatro volúmenes: "Historia y evolución de la colonización agraria en España" publicada entre los años 1986 y 1994 por los Ministerios de Agricultura, de Obras Públicas y de las Administraciones Públicas, representa la recopilación más completa de la producción bibliográfica sobre la colonización desde distintas perspectivas disciplinares, incluida, en el volumen IV, la de la antropología social a cargo de Carlos Giménez Romero.

${ }^{16}$ A partir de esa fecha, las referencias bibliográficas sobre la colonización en Andalucía son más bien escasas: J. Cruz, J. Ojeda y F. Zoido (1980), A. Sánchez López (1980), J. Bosque Maurel (1984), A. T. Reguera (1983, 1984 y 1986), J.M. Porro Gutiérrez (2002) y el capitulo 3 del volumen IV de "Historia y Evolución de la Colonización Agraria en España" (1994), dedicado a la Zona regable del Bajo Guadalquivir.

${ }^{17}$ Los autores hacen referencia al poblado de Calonge (Palma del Rio), con colonos procedentes de Bujaraiza (Jaén), expropiados por la construcción del pantano de El Tranco.

${ }^{18}$ El citado capítulo sobre el Bajo Guadalquivir, del volumen IV de la obra editada en 1994 por el MAPA, a pesar de estar redactado por un equipo de tres antropólogos, no aborda, en nuestra opinión, cuestiones de tanto interés para la antropologia como los procesos de etnogénesis, es decir, "de formación, consolidación y expresión de una comunidad" (tal como se afirma en la página 27 de dicho volumen al enunciar las unidades de análisis), ni se estudian las trans formaciones en la cosmovisión de los individuos que cambian de posición en las relaciones de producción al convertirse en colonos y, finanalmente, quedan ocultos los procesos de reivindicación de autonomía municipal ya iniciados en el momento de realización del reducido periodo de trabajo de campo.

${ }^{19}$ Durante la elaboración del expediente para la Declaración de Patrimonio de la Humanidad de las ciudades renacentistas de Úbeda y Baeza, el equipo de técnicos, seleccionados por la Consejería de Cultura, estuvimos considerando la posibilidad de orientar la solicitud hacia la categoría de Paisaje Cultural, añadiendo a los valores monumentales y arquitectónicos de ambas ciudades el valor cultural de la particular morfologia del cultivo del olivar. Finalmente se rechazó esa posibilidad y ambas ciudades fueron declaradas Patrimonio de la Humanidad en 2003 por su valor monumental. Evidentemente, no pretendemos aquí retomar ese debate para dilucidar si los poblados de colonización son susceptibles de integrase en la Lista del Patrimonio de la Humanidad. No todo lo que es paisaje cultural tiene que estar incluido en esa relación selectiva.

${ }^{20}$ Esta propuesta en particular no sería totalmente pionera. En la Guía para la Puesta en Valor del Patrimonio del Medio Rural Andaluz haciamos mención tanto al proyecto de Recopilación de la memoria Colectiva de la Comarca de Tentudía en Badajoz, en la que nos consta la participación del antropólogo Rufino Acosta Naranjo, como a la iniciativa para la creación del Museo de la Memoria en Castellar (Jaén).

${ }^{21}$ Una iniciativa de este tipo es ya una realidad en Cataluña con la oferta de itinerarios culturales que vinculan a las colonias industriales de la provincia de Barcelona (Ver diario El Pais, suplemento El Viajero, 8 de enero de 2005)

\section{Bibliografía}

BOSQUE MAUREL, J. (1984) Del INC al IRYDA: análisis de los resultados obtenidos por la politica de colonización posterior a la Guerra Civil. Agricultura y Sociedad, $n^{\circ} 32,1984$, pp.153-159

CRUZ, J., OJEDA, J. y ZOIDO, F. (1980) Explotación familiar y estrategias campesinas en los nuevos regadios béticos. Agricultura y Sociedad, n 17, 1980, pp. 11-67
GODELIER, M. (1990) Lo material y lo ideal. Madrid: Taurus. 1990

HALBWACHS, M. (1950) La memoire collective. Paris: P.U.F. 1950

HALBWACHS, M. (2004) Los marcos sociales de la memoria. Barcelona: Anthropos

HERNÁNDEZ RAMíREZ, J. (1999) El Cerro del Águila e HYTASA: Culturas del trabajo, sociabilidad e imágenes de identificación. Sevilla: Diputación Provincial. 1999.

MORENO, I. (1991) Identidades y rituales. Estudio introductorio. En PRAT, J. et al. (eds.) Antropologia de los pueblos de España. Madrid: Taurus Universidad. 1991. pp. 601-637

PALENZUELA, P. (1995) Las culturas del trabajo. Una aproximación antropológica. Sociología del Trabajo. Nueva Época, n²4, 1995, pp. 3-28

PALENZUELA, P, y HERnÁNDEZ, J. (1995b) Poner Monachil en el mapa. Estudio antropológico de un proceso de transformación cultural. Granada: Universidad de Granada-Diputación Provincial de Granada.

PALENZUELA, P. (2000) Guía para la Puesta en Valor del Patrimonio del Medio Rural Andaluz. Sevilla: Consejería de Agricultura y Pesca.

PALENZUELA, P. (2000b) El paisaje como patrimonio etnológico. PH Boletín del IAPH, n 32, 2000, pp. 88-93

PORRO GUTIÉRREZ, J. (2002) Nuevas comunidades y acción estatal: el caso de la colonización agraria en la provincia de Cádiz. Actas del I Congreso de Ciencia Regional de Andalucia. Sevilla. 2002. pp. 976-980

REGUERA RODRígUEZ, A. (1983) Análisis críticos de la intervención estatal en la propiedad de la Zona regable del bajo Guadalquivir. Estudios Humanisticos, $n^{\circ}$ 5, 1983, pp.111-132

REGUERA RODRígUEZ, A. (1984) Criterios para la distribución del hábitat en regadios de realización estatal: el caso del Bajo Guadalquivir. Revista de Estudios Andaluces, $n^{\circ} 2$, 1984. pp. 89-98

REGUERA RODRíGUEZ, A. (1986) Transformación del espacio y política de coIonización: el Bajo Guadalquivir. León: Universidad de León. 1986

ROMERO, J.J. y ZOIDO, F. (1977) Colonización agraria en Andalucia. Sevilla: Instituto de Desarrollo Regional. 1977

SABUCO, A. (2002) ¡Por fin somos Pueblo! Movimientos segregacionistas y sistemas de identidades en la Isla Mayor del Guadalquivir. Tesis Doctoral. Sevilla: Universidad de Sevilla. 2002

SÁNCHEZ LÓPEZ, A. (1980) La colonización y el mantenimiento de la dependencia entre la pequeña y gran propiedad: el caso del Viar. Agricultura y Sociedad, $n^{\circ} 17$, Madrid. 1980, pp. 69-108

VV. AA. (1986-1994) Historia y evolución de la colonización agraria en España. 4 vol. Madrid: MAPA, MOP y MAP. 1994 